\title{
Neurobehavioural effects of professional abalone diving
}

\author{
A M WILLIAMSON, ${ }^{1}$ B CLARKE, ${ }^{1}$ C EDMONDS ${ }^{2}$ \\ From the NSW Department of Industrial Relations, ${ }^{1}$ Division of Occupational Health, PO Box 163, Lidcombe \\ 2121, and Diving Medical Centre, ${ }^{2}$ Cremorne 2090, Australia
}

\begin{abstract}
In a study of 33 commercial abalone divers from the Port Lincoln area of South Australia nervous system function was examined using a battery of neurobehavioural tests. Their performance was compared with that of non-diver controls matched for age, sex, education level, job type, language abilities, and cigarette and alcohol consumption. Abalone divers showed significantly poorer vision, learning, and short term memory performance and increased tremor relative to their controls. The reaction time of abalone divers, however, was as fast as or significantly faster than that of controls but their error rates were much higher, indicating that abalone divers were sacrificing speed for accuracy. Despite their apparent risk taking approach to these tests, the performance of abalone divers suggests some impairment of nervous system function.
\end{abstract}

The effects of long term exposure to the underwater environment such as is encountered by professional divers are not well understood. Whereas the effects of deep diving has attracted a considerable amount of research attention ${ }^{1}$ few studies have focused on the long term effects of shallow water exposure.

One area in particular, the effect of long term effects of repeated shallow water exposure on the nervous system, is open to question. Even though there is a significant amount of clinical and anecdotal evidence that professional divers suffer damage to the nervous system, neurological and behavioural function have not been examined systematically.

A few scattered reports have detailed the neurological effects of decompression sickness. One of the earliest described diffuse damage to a range of areas in the nervous system as well as neurotic and psychosomatic symptoms in caisson workers. ${ }^{2}$ Subsequent work has shown that divers suffer similar nervous system effects of decompression sickness. ${ }^{34}$ Neuropsychological testing showed that $90 \%$ of commercial divers who reported at least one episode of decompression illness affecting the central nervous system had abnormalities compared with commercial divers with no reported history of decompression sickness, and it was concluded that central nervous system disturbance after decompression sickness in divers is more common than had been previously

Accepted 27 August 1986 appreciated. ${ }^{4}$

There are several other potential causes of nervous system damage in professional divers, the most notable being air embolism and carbon monoxide poisoning due to contaminated air. A study of the effects of near-miss diving accidents mostly due to air embolism ${ }^{5}$ showed that these divers had poorer spatial memory and complex sensory motor functions compared both with divers who had no reported accidents and non-divers. The effects of carbon monoxide poisoning have not been studied in divers but there is considerable evidence from other occupational groups that even low level exposure to carbon monoxide produces severe reductions in vigilance, some visual functions, and time estimation abilities. ${ }^{6}$

Probably the nervous system is at risk in divers who are exposed to these hazards. None of the studies conducted to date, however, has attempted to ascertain the extent of exposure or the circumstances that led up to the damage nor to determine systematically whether particular neurobehavioural functions are being damaged.

The present study was an attempt to investigate neurobehavioural function in a working group of professional abalone divers. The tests used were from a battery designed to investigate the effects of various occupational hazards and has been successful in detecting the neurobehavioural effects of occupational exposure to inorganic mercury ${ }^{7}$ and inorganic lead. ${ }^{8}$ 


\section{Method}

DESCRIPTION OF PARTICIPANTS

Thirty three professional abalone divers were tested. All were men from the Port Lincoln area of South Australia. Twenty two were currently working and 11 were ex-divers. Of the ex-divers, most had only recently given up diving and many still did relief diving. Most of the group did casual work in conjunction with their diving such as fishing and farming since they dived an average of only 91.8 days $(\mathrm{SD}=35 \cdot 6)$ a year.

A group of 33 male non-divers were also tested for comparison purposes. This control group was matched with the diver group in terms of age, education level, and their consumption of cigarettes and alcohol. Virtually all members of both groups (100\% of divers, $91 \%$ controls) were either born in Australia or had been residents for more than 15 years. Only one participant, originally from Britain, had been a resident for less than 10 years. So far as possible, the control group was selected to match the jobs, both diving and casual, of the diver group. For example, if the diver also did a skilled job a skilled worker was chosen as his control.

\section{NEUROBEHAVIOURAL TESTS}

The tests were chosen on the basis of information processing theory ${ }^{9}$ and consisted of the following.

\section{Critical flicker fusion}

Critical flicker fusion is a perceptual test in which a critical flicker fusion (CFF) threshold is obtained for each eye. An electronic device was used similar to that described elsewhere. ${ }^{10}$ Presentation of the light source was by a descending method of limits. ${ }^{11}$

Seven trials were presented to each eye. Each trial began with the presentation of a steady light, the switching frequency of which decreased at a constant rate of $2 \mathrm{~Hz} / \mathrm{s}$ until terminated by the subject pressing a button, indicating first awareness of flicker. The mean critical flicker fusion threshold value was calculated using the last five trials for each eye.

\section{Hand steadiness}

The hand steadiness test is a psychomotor coordination test. The apparatus used consisted of two $17.5 \mathrm{~cm} \times 5.75 \mathrm{~cm}$ plates bolted on to a single perspex back and held vertical at an adjustable height by a retort stand. Each plate independently formed an electric circuit when hit or touched by a stylus. The subject was required to hold the stylus in a $5 \mathrm{~mm}$ diameter hole between the two plates with his arm outstretched keeping it as steady as possible for one minute. The number and duration of touches on upper and lower plates were recorded independently for the three consecutive 20 second periods.
Bourdon-Wiersma test

The Bourdon-Wiersma test is one of sustained atter $\frac{\mathbb{B}}{2}$ tion and psychomotor speed. ${ }^{12}$ The subject was. required to mark every group of four dots on a page of 50 rows of 25 groups of three, four, or five dot groups as quickly and as accurately as possible in five minutes. The total number of groups examined (tare gets tracked) and the number of missed four doof groups (errors) were noted and expressed as a per centage of the total number of groups on the page.

\section{Digit symbol test}

The digit symbol test is a measure of psychomoto performance using paper and pencil. It is a subtest of the Wechsler adult intelligence (WAIS) test battery and consists of a sheet containing 100 small blan squares arranged in four rows. Each square is paired with a randomly assigned number from one to nines Above these rows is a printed key that pairs each number with a different nonsense symbol-for examp ple $7=\wedge$. After a practice trial on the first seve $\vec{n}$ squares, the subject was required to fill in as many the blank squares with the symbol paired to the number above the space in 90 seconds. The number 8 correct responses was calculated and converted to an age related standard score obtainable from the WAIS-R manual.

\section{Reaction time and Sternberg tasks}

The apparatus has been described elsewhere. ${ }^{14}$ It wa used for both reaction time and Sternberg tasks.

Reaction time-Subjects were tested in a simple reaction time paradigm. Beginning with the inde finger of the preferred hand on the starting point, subjects were required to press the button closest to the preferred hand as quickly as possible when an $\bar{\theta}$ appeared on the display (the stimulus was always a O). Twenty trials were given and the mean reaction time was calculated from the last ten. After con₹ pletion of the Sternberg task, a further ten trials were given and the mean calculated.

Sternberg task-A set of two, three, four, or five randomly selected digits from 0-9 was presente. orally to the subject and he was asked to remember itu A digit was then displayed on the response box to which the subject was required to respond with the Yes button if the digit was included in the memory of positive set or the No button if the digit was nब (negative set). A total of 48 presentations was made iक which each type of digit set (two, three, four, or five digits) was represented twice and each individual sef was tested six times, three each for positive and nega tive responses. The mean reaction time was calculated for each type of digit set, as well as total number of errors. 
Short term memory (STM) (paired associates)

The short term memory test items consisted of five pairs of high (real) association (greater than $90 \%$ associative value) alphabetic trigrams selected from the list compiled by Archer. ${ }^{15}$ The trigram pairs were presented individually using a slide projector at a rate of one per five seconds. Once all five pairs had been shown, the first member of each pair was shown in a random order and the subject was required to write down the matching member. This sequence was repeated until all five trigrams were recalled correctly or after six trials. The number of trigrams correctly recalled on the first trial and the number of trials to criterion or the failure to reach criterion were recorded.

\section{Long term memory (LTM)}

The long term memory test was a continuation of the paired associate test described above. Without prior warning, the subjects were asked to recall the trigrams they had learnt earlier (about 90 minutes before). The first member of each trigram pair were presented and the number of trigrams correctly recalled was recorded.

\section{PROCEDURE}

Diving histories were obtained by interviewing each diver and a questionnaire was completed by each participant to cover general biographical information such as age, education level, ethnic background, waking and sleeping habits, cigarette and alcohol consumption, and medication. Three tests, the paired associates STM test, the Bourdon-Wiersma test, and the digit symbol test, were carried out in groups of five or six. The remainder were performed individually. In all cases the group tests were carried out first to allow sufficient time between learning and the LTM test for the paired associates. All other tests were carried out in random order.

\section{STATISTICAL ANALYSIS}

There were two basic comparisons of interest; the difference between the divers (including current and ex-divers) and their controls on each test and the difference between performances of current divers and ex-divers on each test. In virtually all cases the analysis was performed by $t$ test or analysis of variance. For the paired associates STM and LTM tests, however, the Wilcoxon rank sum test ${ }^{16}$ was used because the distribution of scores clearly departed from normal and the trials to criterion measure was ordinal.

For two tests, the Bourdon-Wiersma and the digit symbol matched controls were not available at the time of writing. Consequently, for the digit symbol test each individual's score was converted to the age corrected standard score available for the test from large population assessments and then the diver group was compared with the population norm. Unfortunately, there are no population standards from the Bourdon-Wiersma test so the only comparison reported for this test was between current and ex-divers.

\section{Results}

Analysis of the effectiveness of the matching process showed that divers and controls were not statistically significantly different in terms of age $\left(\chi_{(3)}^{2}=0.64\right.$, NS) or education level $\left(\chi_{(3)}^{2}=0.41\right.$, NS) (table 1$)$. Similar percentages of the two groups smoked, and the amount smoked per week, did not differ significantly $\left(t_{(32)}=0.82\right.$, NS). More divers admitted to drinking alcohol than non-divers but the amount consumed did not differ significantly $\left(\mathrm{t}_{(32)}=0.62\right.$, NS).

Similar analysis between current and ex-divers showed that the ex-divers were older $\left(\chi_{(3)}^{2}=14 \cdot 98, p\right.$ $<0.01)$ but that their educational backgrounds were comparable $\left(\chi_{(3)}^{2}=3.39\right.$, NS). Only one ex-diver smoked and similar numbers in the two groups admitted to consuming alcohol. Ex-divers, however, consumed significantly greater amounts of alcohol $\left(t_{(10)}\right.$ $=5.7, \mathrm{p}<0.01$ ).

Comparison of the diving characteristics of current and ex-divers showed that they did not differ significantly in terms of duration of diving exposure $\left(t_{(32)}=1.44, N S\right)$, the number of instances of decompression sickness $\left(\chi_{(4)}{ }_{(4)}=2 \cdot 42\right.$, NS) - or the incidence of neurological symptoms and decompression sick-

Table 1 Comparison of characteristics of current and ex-divers and non-divers. Controls showing percentages means and standard deviations or medians and ranges where appropriate

\begin{tabular}{|c|c|c|c|c|}
\hline & Current divers & Ex-divers & Total divers & Non-divers \\
\hline $\begin{array}{l}\text { Age (median years) } \\
\text { Education (median years) } \\
\text { \% Smoking } \\
\text { No of cigarettes smoked a week (mean) } \\
\% \text { Using alcohol } \\
\text { Alcohol/wk (mean, g) }\end{array}$ & $\begin{array}{l}35 \cdot 0(21-48) \\
11 \cdot 8(6-16) \\
31 \cdot 8 \\
20 \cdot 7(6 \cdot 1) \\
72 \cdot 7 \\
84 \cdot 8(93 \cdot 5)\end{array}$ & $\begin{array}{l}44 \cdot 5(40-53) \\
11 \cdot 2(6-17) \\
10 \cdot 0 \\
25 \cdot 0(\text { na) } \\
80 \cdot 0 \\
157 \cdot 8(116 \cdot 9)\end{array}$ & $\begin{array}{l}40 \cdot 0(21-53) \\
11 \cdot 5(6-17) \\
24 \cdot 2 \\
21 \cdot 3(5 \cdot 8) \\
80 \cdot 0 \\
115 \cdot 0(103 \cdot 8)\end{array}$ & $\begin{array}{l}40 \cdot 0(20-59) \\
12 \cdot 1(6-17) \\
27 \cdot 3 \\
20 \cdot 1(4 \cdot 6) \\
54 \cdot 5 \\
107 \cdot 0(82 \cdot 94)\end{array}$ \\
\hline
\end{tabular}


ness $\left(\chi^{2}{ }_{(1)}=0.02\right.$, NS) (table 2). They differed, however, in the maximum depth reached on an average dive $\left(t_{(32)}=2.06, p<0.05\right)$. Current divers typically dived much deeper than ex-divers.

The diver group had significantly lower critical flicker fusion thresholds than the controls as shown by analysis of variance ( 2 factor, repeated measures on one factor, group main effect $\left(F_{(1,64)}=10.99, p\right.$ $<0.01)$ ). There was no difference in the threshold of each eye for either group (eye main effect $F_{(1,64)}=$ $1 \cdot 1, \mathrm{NS}$ ) and the deficiency in the diver group was the same for each eye (interaction effect $F_{(1,64)}=0 \cdot 18$, NS).

A similar comparison between current and exdivers ( 2 factor analysis of variance, repeated measures on one factor) showed no significant differences between them (group main effect $F_{(1,31)}=2 \cdot 85$, NS) for either eye (interaction $F_{(1,31)}=0.48$, NS) nor between the thresholds for either eye (eye main effect $\left(F_{(1,31)}=0.77\right.$, NS) (table 3).

Analysis of reaction time by $t$ tests showed no significant differences between divers and controls $\left(t_{(32)}=1 \cdot 71, N S\right)$ nor between current and ex-divers
Table 2 Comparison of the diving experience of current an ex-divers showing extent of exposure, maximum depth reached on a typical dive, and incidence of decompression sickness per individual with and without neurological symptoms

\begin{tabular}{|c|c|c|c|}
\hline & $\begin{array}{l}\text { Current } \\
\text { divers }\end{array}$ & $E x$-divers & $\begin{array}{l}\text { Total } \\
\text { divers }\end{array}$ \\
\hline $\begin{array}{l}\text { Exposure (mean, } \mathrm{h} \text { ) } \\
\text { Maximum depth (mean, } \mathrm{ft} \text { ) }\end{array}$ & $\begin{array}{l}4685 \\
(3603) \\
68 \cdot 6 \\
(16 \cdot 1)\end{array}$ & $\begin{array}{l}6350 \\
(2877) \\
56 \cdot 5 \\
(15 \cdot 8)\end{array}$ & $\begin{array}{l}5205 \\
(3436) \\
64 \cdot 8 \\
(16 \cdot 8)\end{array}$ \\
\hline $\begin{array}{l}\text { Incidence of decompression } \\
\text { sickness per individual (median) } \\
\text { \% Reporting neurological } \\
\text { symptoms with decompression } \\
\text { sickness }\end{array}$ & $\begin{array}{l}3 \cdot 5 \\
(0-100)\end{array}$ & $\begin{array}{l}4 \\
(0-15)\end{array}$ & $\begin{array}{l}3.75 \\
(0-100) \stackrel{G}{0} \\
45\end{array}$ \\
\hline
\end{tabular}

The results of the hand steadiness test were anats ysed by two 3 factor analyses of variance (repeateq measures on two factors) (table 4). Significantly moß off target touches were made by divers than controts (group main effect $F_{(1,64)}=10.61, p<0.01$ ), partic ularly to the lower plate (interaction $F_{(1,64)}=7 \cdot 99$,

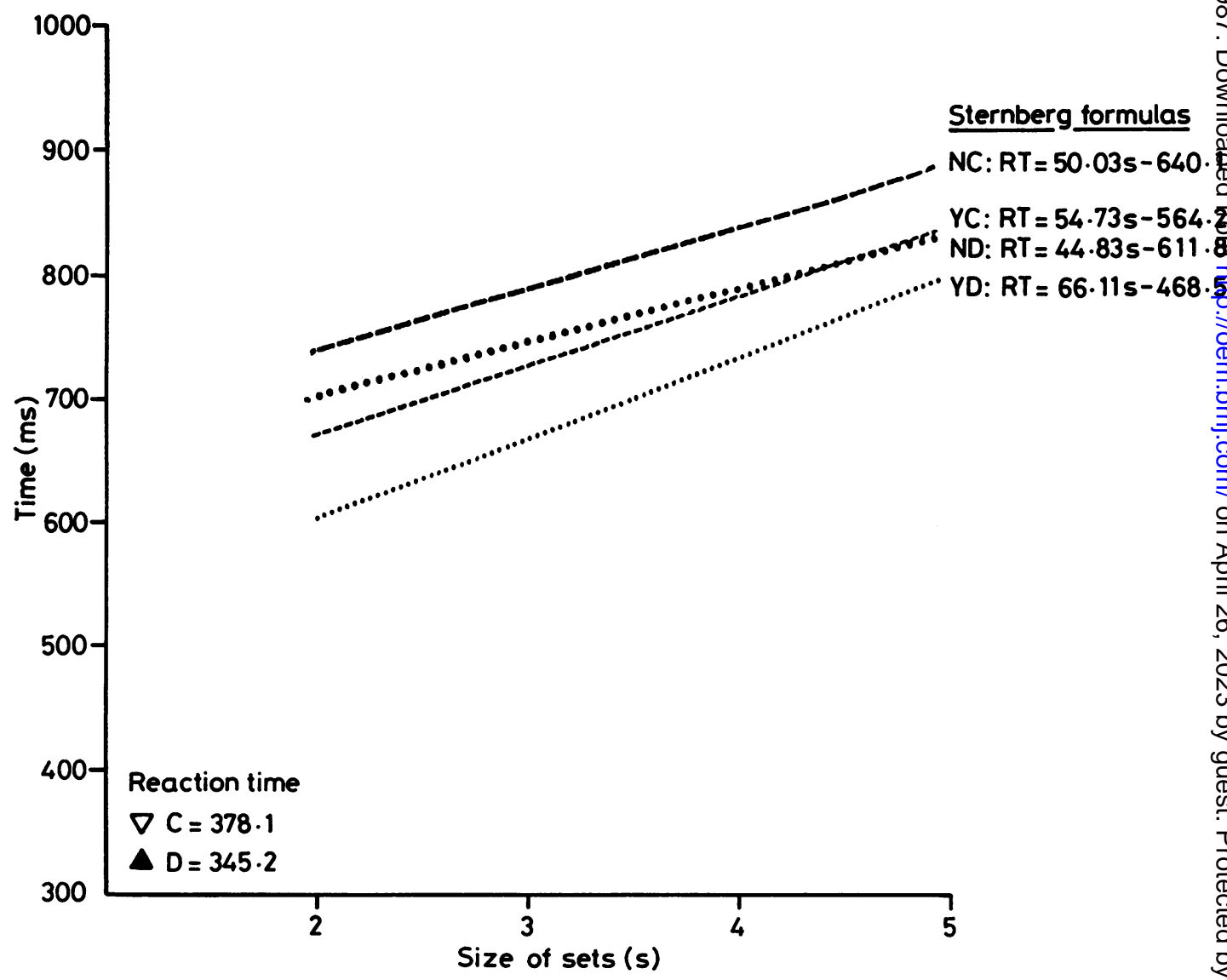

Fig 1 Results of reaction time and Sternberg memory tests, showing mean reaction time for divers (D) and non-divers $(C), 8$ and lines of best fit for Sternberg memory tests showing Yes responses ( $Y$ ) for divers and non-divers, and No responses ( $N$ ) 席 divers and non-divers. 


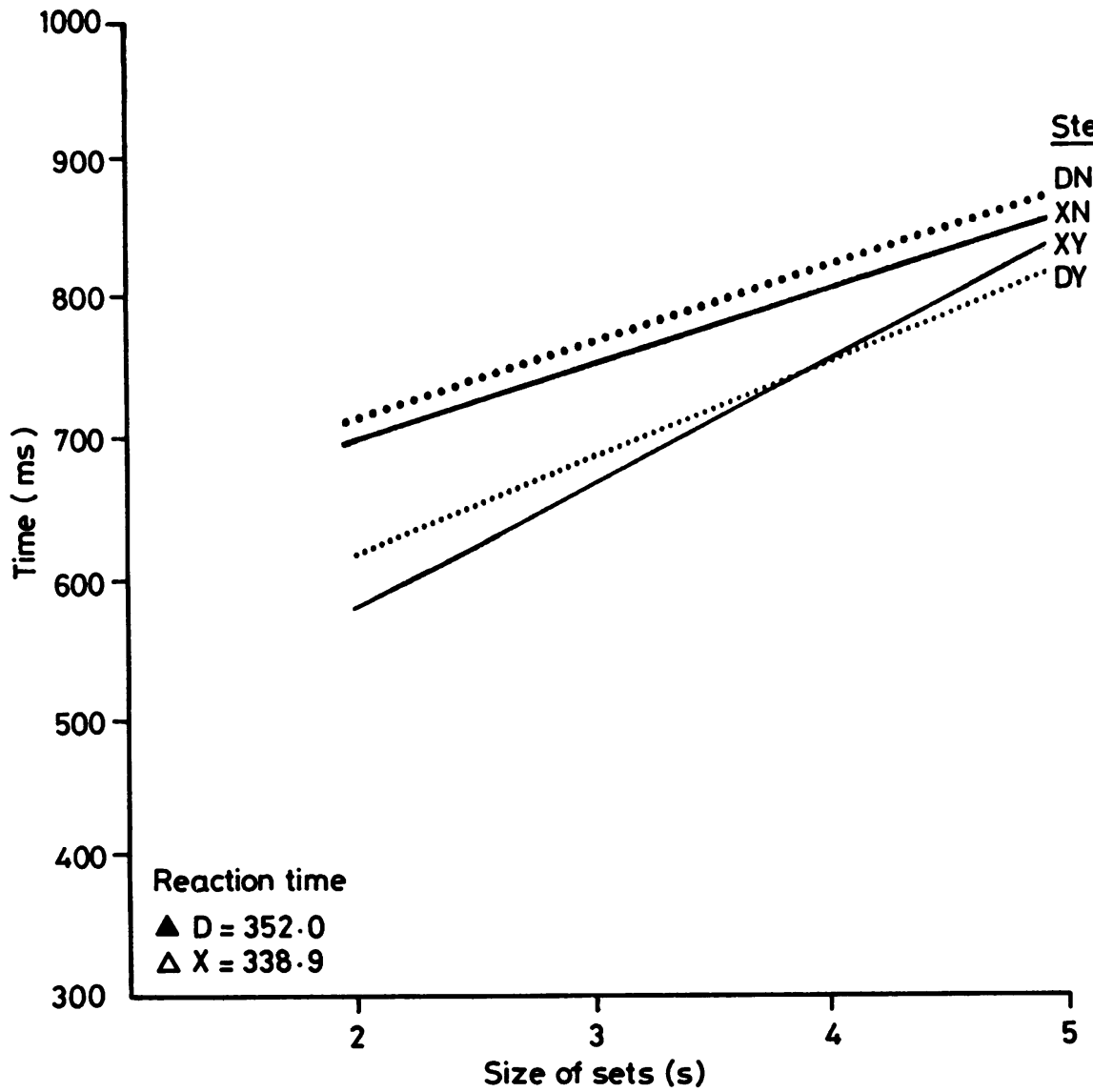

Fig 2 Results of reaction time and Sternberg memory tests, showing mean reaction time for divers ( $D)$ and ex-divers (X), and lines of best fit for Sternberg memory tests showing Yes responses ( $Y$ ) for divers and ex-divers, and No responses ( $N$ ) for divers and ex-divers.

Table 3 Results of the critical flicker fusion test showing means and standard deviations for divers and controls and current divers and ex-divers

\begin{tabular}{lllll}
\hline & Divers $(n=33)$ & Non-divers $(n=33)$ & $\begin{array}{l}\text { Current } \\
\text { divers }(n=22)\end{array}$ & Ex-divers $(n=11)$ \\
\hline Critical flicker fusion left eye & $34 \cdot 1(4 \cdot 7)$ & $37 \cdot 9(4 \cdot 5)$ & $34 \cdot 9(4 \cdot 7)$ & $32 \cdot 6(4 \cdot 6)$ \\
Critical flicker fusion right eye & $33 \cdot 7(4 \cdot 89)$ & $37 \cdot 4(5 \cdot 00)$ & $34 \cdot 7(4 \cdot 3)$ & $31 \cdot 6(5 \cdot 6)$ \\
\hline
\end{tabular}

Table 4 Hand steadiness test results for divers and controls showing means and standard deviations for time off target and the number of off target touches to the upper and lower plate in each consecutive 20 second time period

\begin{tabular}{|c|c|c|c|c|c|c|}
\hline & \multicolumn{3}{|c|}{ Divers time period } & \multicolumn{3}{|c|}{ Controls time period } \\
\hline & $l s t$ & $2 n d$ & $3 r d$ & $I s t$ & $2 n d$ & $3 r d$ \\
\hline \multicolumn{7}{|c|}{ Off target touches: } \\
\hline $\begin{array}{l}\text { Upper } \\
\text { Lower }\end{array}$ & $\begin{array}{l}23.9(9 \cdot 3) \\
33.4(9.9)\end{array}$ & $\begin{array}{l}21 \cdot 8(9 \cdot 8) \\
34 \cdot 8(11 \cdot 6)\end{array}$ & $\begin{array}{l}21 \cdot 2(13 \cdot 7) \\
33 \cdot 9(14 \cdot 6)\end{array}$ & $\begin{array}{l}18 \cdot 9(8 \cdot 8) \\
24 \cdot 8(11 \cdot 6)\end{array}$ & $\begin{array}{l}18 \cdot 3(8 \cdot 7) \\
25 \cdot 9(9 \cdot 4)\end{array}$ & $\begin{array}{l}16 \cdot 6(9 \cdot 3) \\
23 \cdot 1(10 \cdot 5)\end{array}$ \\
\hline $\begin{array}{l}\text { Time off target: } \\
\text { Upper } \\
\text { Lower }\end{array}$ & $\begin{array}{l}19 \cdot 8(10 \cdot 5) \\
32 \cdot 5(17 \cdot 7)\end{array}$ & $\begin{array}{l}18 \cdot 8(10 \cdot 4) \\
31 \cdot 6(13 \cdot 5)\end{array}$ & $\begin{array}{l}17.7(12.9) \\
31.6(21.7)\end{array}$ & $\begin{array}{l}16 \cdot 8(13 \cdot 1) \\
26 \cdot 0(17 \cdot 3)\end{array}$ & $\begin{array}{l}16 \cdot 1(9 \cdot 9) \\
25 \cdot 2(15 \cdot 7)\end{array}$ & $\begin{array}{l}15 \cdot 7(13 \cdot 7) \\
22 \cdot 3(16.8)\end{array}$ \\
\hline
\end{tabular}


Table 5 Results of the hand steadiness test showing means and standard deviations for off target touches and time off target $\frac{2}{8}$ upper and lower plate for each of three consecutive 20 second periods comparing current and ex-divers

\begin{tabular}{|c|c|c|c|c|c|c|}
\hline & \multicolumn{3}{|c|}{ Current divers time period } & \multicolumn{3}{|c|}{ Ex-divers time period } \\
\hline & Ist & $2 n d$ & $3 r d$ & lst & $2 n d$ & $3 r d$ \\
\hline \multicolumn{7}{|l|}{ Off target touches: } \\
\hline $\begin{array}{l}\text { Upper } \\
\text { Lower }\end{array}$ & $\begin{array}{l}22 \cdot 8(9 \cdot 5) \\
34 \cdot 1(9 \cdot 1)\end{array}$ & $\begin{array}{l}21 \cdot 5(9 \cdot 8) \\
36 \cdot 4(12 \cdot 1)\end{array}$ & $\begin{array}{l}19 \cdot 8(11 \cdot 2) \\
33 \cdot 6(12 \cdot 6)\end{array}$ & $\begin{array}{l}26 \cdot 1(7 \cdot 9) \\
32 \cdot 0(10 \cdot 8)\end{array}$ & $\begin{array}{l}22 \cdot 4(9 \cdot 3) \\
31 \cdot 7(8 \cdot 9)\end{array}$ & $\begin{array}{l}23.9(16.8) \\
34.4(17.4)\end{array}$ \\
\hline \multicolumn{7}{|l|}{ Time off target: } \\
\hline
\end{tabular}

$<0.01)$. Off target touches were significantly more frequent to the lower plate compared with the upper plate in both groups (plate main effect $F_{(1,64)}=$ $103.01, p<0.01$ ) but there was no change in off target touches over the period of the test for either group (time main effect $F_{(2,128)}=1 \cdot 79$, NS).

The groups were not significantly different overall in terms of the time they spent off target in this test (group main effect $F_{(1,64)}=2.83$, NS). Again, the lower plate was the site of most time off target for both groups (plate main effect, $F_{(1,64)}=82 \cdot 89, p<$ $0.01)$ but by the diver group in particular (interaction $\left.F_{(1,64)}=4 \cdot 15, p<0.05\right)$. There was no change in time off target over the period of the test for either group as before $\left(\mathrm{F}_{(2,128)}=1 \cdot 15, \mathrm{NS}\right)$.

Comparison of current and ex-divers on this test showed no significant differences in their hand steadiness for either off target touches $\left(F_{(1,31)}=0.01, \mathrm{NS}\right)$ or time off target $\left(\mathrm{F}_{(1,31)}=1 \cdot 57, \mathrm{NS}\right)$ (table 5). The lower plate was the site of most off target movement in both groups $\left(\mathrm{F}_{(1,31)}=50.3, \mathrm{p}<0.01\right)$ for time; $\left(F_{(1,31)}=75.8, p<0.01\right)$ and for touches but to the same extent in both groups $\left(F_{(1,31)}=0.98, N S ; F_{(1,31)}\right.$ $=3 \cdot 6$, NS for time and touches respectively).

For the Bourdon-Wiersma test as mentioned earlier, the only comparison that could be made was between current and ex-divers. Analysis by $t$ tests

Table 6 Results of the Bourdon-Wiersma test showing means and standard deviations for number of targets tracked and percentage errors for current divers and ex-divers

\begin{tabular}{lll}
\hline & Current divers & Ex-divers \\
\hline $\begin{array}{l}\text { Targets tracked } \\
\% \text { Errors }\end{array}$ & $147 \cdot 64(27 \cdot 5)$ & $146 \cdot 18(27 \cdot 6)$ \\
\hline
\end{tabular}

Table 7 Digit symbol test results for total diver group and for current and ex-divers showing means and standard deviations

\begin{tabular}{llll}
\hline & $\begin{array}{l}\text { Total } \\
\text { diver group }\end{array}$ & Current & Ex-divers \\
\hline Scaled score & $8 \cdot 9(2.09)$ & $8 \cdot 8(2 \cdot 17)$ & $9 \cdot 2(1.91)$ \\
\hline
\end{tabular}

showed that there were no significant differences between these groups either in terms of the number of targets searched over the time of the test $\left(t_{(31)}=0 \cdot 1\right.$, NS) or the number of targets missed (errors, $t_{(31)}$ $0 \cdot 11$, NS) (table 6).

Compared with the population's standard scort divers showed significantly poorer performance of the digit symbol test $\left(\mathrm{t}_{(31)}=2.74, \mathrm{p}<0.01\right)$; how ever, again, within the diver group there was no significant difference between the performance of cu传 rent and ex-divers $\left(t_{(31)}=0.65\right.$, NS) (table 7).

The results of the Sternberg test are shown in figs $\overrightarrow{\$}$ and 2. Lines of best fit were calculated for speed of response against the size of the memory set for bogt positive (actively remembered or Yes items) and nege tive (items not in memory set or No items) memo sets for each group. Comparison of the slopes of the lines for divers and non-divers showed that for the positive set only, the cognitive component of the test took significantly longer for the diver group (positige set, $\mathrm{t}_{(64)}=4.83, \mathrm{p}<0.01$; negative set, $\mathrm{t}_{(64)}=-1.94$, NS). Analysis of the intercepts also show significant differences between divers and controls for both memory sets (positive set, $\mathrm{t}_{(64)}=-11.07, \mathrm{p}$ 0.01 ; negative set, $\mathrm{t}_{(64)}=-2.86, \mathrm{p}<0.01$ ) but 总 both cases divers were faster than non-divers. Dive made significantly more errors on this tests than controls $(1.58 \pm 1.12$ for divers and $0.62 \pm 0.95$ for coo trols, $\left.\mathrm{t}_{(64)}=-3.28, \mathrm{p}<0.01\right)($ table 8$)$.

Comparison of current and ex-divers showed significant differences for cognitive and movemet (intercept) components for the positive memory set (slope, $\mathrm{t}_{(31)}=3.66, \mathrm{p}<0.01$; intercept, $\mathrm{t}_{(31)}=3.873$, $\mathrm{p}<0.01)$. There were no significant differences within the divers for the negative set (slope, $t_{(31)}$

Table 8 Errors on the Sternberg memory test for comparisons between divers and non-divers and current and ex-divers. Means and standard deviations are shown

\begin{tabular}{lllll}
\hline & Divers & Non-divers & Current divers & Ex-divers \\
\hline $\begin{array}{l}\text { Sternberg test } \\
\text { errors }\end{array}$ & $1.58(1 \cdot 12)$ & $0.62(0.95)$ & $1.4(1.01)$ & $1.9(1 \cdot 1)$ \\
\hline
\end{tabular}


Table 9 Results of the paired associates test showing medians and ranges for the comparisons; divers with non-divers and current divers with ex-divers. The STM measure, number correct, trials to criterion, and percentage of each group reaching criterion are show'n as well as the LTM number correct measure

\begin{tabular}{lllll}
\hline & Divers & Non-divers & Current divers & Ex-divers \\
\hline STM. No correct & $2 \cdot 0(0-4)$ & $2 \cdot 0(0-5)$ & $2 \cdot 0(0-4)$ & $2 \cdot 0(0-3)$ \\
Trials to criterion & $4 \cdot 5(2->6)$ & $3 \cdot 0(1->6)$ & $3 \cdot 5(2->6)$ & $3 \cdot 0(2->6)$ \\
$\%$ Reaching criterion & $60 \cdot 6$ & $75 \cdot 6$ & $63 \cdot 6$ & $50 \cdot 0$ \\
LTM. No correct & $2 \cdot 5(0-5)$ & $3 \cdot 0(1-5)$ & $3 \cdot 0(0-5)$ & $2 \cdot 0(1-5)$ \\
\hline
\end{tabular}

0.31 , NS; intercept, $t_{(31)}=1.00$, NS). Similarly, the number of errors was no different between the two diver groups (1.41 and 1.91 for current and ex-divers respectively, $\mathrm{t}_{(31)}=1 \cdot 22$, NS).

There were no differences between the performances of divers and non-divers on the short term memory measure of the paired associates test, the number of trigrams correct on the first round (Wilcoxon rank sum test $\mathrm{z}=-0 \cdot 58$, NS). Divers took significantly more trials to learn the set of trigrams than controls $(z=2.42, p<0.01)$. Whereas more divers failed to reach the criterion of all correct (39.3\% compared with $27 \cdot 3 \%$ for non-divers), there was no significant difference in long term memory test performance between divers and controls $(\mathrm{z}=-1 \cdot 2$, NS).

The same comparisons for the paired associates group of tests showed no significant differences between current and ex-divers for the STM test (number correct, $z=0 \cdot 76, N S)$ trials to criterion $(z=0 \cdot 19$, NS) nor the LTM test $(z=0.48$, NS) (table 9).

\section{Discussion}

Abalone divers clearly showed poorer performance on several neurobehavioural tests than would be expected based on that of carefully matched nondivers. This was true for both currently working and retired divers. In particular, abalone divers showed poorer CFF thresholds, poorer hand steadiness, lower digit symbol scores, were less able to learn new material, and in the Sternberg memory test made more errors and showed a poorer ability to cope with increasing memory loads compared with controls. Nevertheless, abalone divers performed as well or better than non-divers in a few tests-namely, the paired associates STM and LTM tests, the negative memory set in the Sternberg test (items not actively being remembered) as well as the reaction time test, and the motor component of the Sternberg test (intercept).

Interpreting this pattern of results from an information processing viewpoint, the most clearcut finding is of depressed CFF thresholds. Reduced CFF thresholds may indicate lowered cortical arousal ${ }^{17}$ or depressed visual function, or both, either at the retina or in the intermediate visual pathway. ${ }^{18}$
This suggestion of visual disturbance in professional divers is in keeping with reported visual effects of decompression sickness in caisson workers ${ }^{2}$ that were attributed to "retinal aeropathy." Visual impairment may also be due to inappropriate use of oxygen for treating decompression sickness or for carbon monoxide toxicity. Oxygen under pressure may be neurotoxic and, in particular, affect the retina in man. ${ }^{19}$

The finding of poorer hand steadiness is consistent with the report of intentional tremor in divers with known histories of decompression sickness ${ }^{4}$ and of psychomotor impairment in divers who had air embolism or hypoxia, or both. ${ }^{5}$ In this study, however, the only psychomotor effects were increased tremor. Reaction time abilities were at least as good as those of non-divers in the reaction time test and even better than non-divers as shown by the motor components of the Sternberg test.

Differences in motivation may possibly be responsible for the superior response times of the diver group. The reaction time test is a simple test of motor speed whereas the Sternberg test is a test requiring both speed and accuracy. Divers may be able to react faster than non-divers on this test because they were sacrificing speed for accuracy. Similarly, divers made significantly more errors than nondivers, indicating either that they often moved before they had made an appropriate decision or that they were not remembering the information correctly in the first place, or both.

The results of the paired associates STM test did not indicate any deficiencies in the short term memory of divers compared with controls but the results of the Sternberg memory test show that divers did not deal with increasing memory loads as well as the controls. The Sternberg test makes it possible to distinguish the cognitive or thinking components of a memory test from problems of responding. ${ }^{14}$ Sternberg's theory predicts that the slope of the line which describes the relation between memory set size and reaction time is an indicator of the relative increase in reaction time with each additional memory item and therefore reflects cognitive elements in the test such as encoding of the information and item matching. Thus the steeper the slope, the more time the individual takes 
cognitively to process the information and the slower the memory process. Since divers had significantly steeper slopes for the actively remembered items (positive set or Yes items) than controls, it must be concluded that they needed more time to process this information before making a response. Both previous studies of divers found that the affected divers were characterised by memory problems. ${ }^{45}$

On the other hand, in this study the cognitive component of the information not actively remembered (negative set or No items) did not differ from that of controls. Sternberg's theory maintains that when presented with an item the individual searches the actively remembered set (Yes set) of items first before deciding that his/her response should be Yes or No. Consequently the slope for the No responses is usually about the same or steeper than that of the Yes responses. For the control group in this study this was true, but the divers were considerably faster in their cognitive responses to the No items than to the Yes items. This suggests again that the divers were trying for speed rather than accuracy. Probably they were only partially completing the search through the remembered set before making the decision in the negative. This would explain, too, why such a high percentage $(74.1 \%)$ of errors were of the No-shouldhave-been-Yes type.

Professional abalone divers are probably a unique group quite apart from any of the neurobehavioural health effects of their chosen occupation. Abalone diving, like other potentially dangerous occupations such as firemen, ${ }^{20}$ probably attracts a high proportion of risk takers. The results of the tests in this study, and possibly from other studies as well, may reflect this performance bias. Therefore the performance of professional divers on tests that can be influenced by incentive or motivational differences-tests requiring speed such as reaction time, for example - may be confounded by their use of different strategies such that deterioration in neurobehavioural functions may be difficult to detect.

Nevertheless, there were detectable differences between divers and their matched controls in visual, short term memory and some psychomotor abilities which are consistent with the findings from previous studies and are suggestive of an impairment of ner $\frac{\pi}{\Phi}$ vous system function.

\section{References}

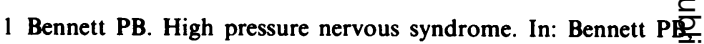
Elliott DH, eds. The physiology and medicine of diving. LoS. Angeles: Best Publishing Co, 1982.

2 Rozsahegyi I. Late consequences of the neurological forms of decompression sickness. Br J Ind Med 1959;16:311-7.

3 Hallenbeck JM, Bove AA, Elliott DH. Mechanisms underlying. spinal cord damage in decompression sickness. Neurologi 1975;25:308-16.

4 Peters BH, Levin HS, Kelly PJ. Neurological forms of decomiv pression illness in divers. Neurology 1977;27:125-7.

5 Vaernes RJ, Eidsvik S. Central nervous dysfunction after neabo miss accidents in diving. Aviat Space Environ Mes 1982;53:803-7.

6 Beard RR, Grandstaff MW. Carbon monoxide and human funct tions. In: Wiess B, Laties VG, eds. Behavioural toxicology. New York: Plenum Press, 1975.

7 Williamson A, Teo R, Sanderson J. Occupational mercurfo exposure and its consequences for behaviour. Int Arch Occu Environ Health 1982;50:273-86.

8 Williamson A, Teo R. Neurobehavioural effects of occupational exposure to lead. $\mathrm{Br} J$ Ind Med 1986;43:374-80.

9 Lindsay PH, Norman DA. Human information processing: an introduction to psychology. Orlando: Academic Press, 1977.

10 Tuttle TC, Wood GD, Grether CB. Behavioural and neurologicapo evaluation of workers exposed to carbon disulfide $\left(\mathrm{CS}_{2}\right)$. Cincinnati: US DHEW (NIOSH), 1977 publ No 77-128.)

11 Guilford JP. Psychometric methods. New York: McGraw HilP 1954.

12 Hanninen H, Lindstrom K. Behavioural test battery for tox icopsychological studies. Helsinki: Institute of Occupation@ Health, 1979.

13 Wechsler D. Wechsler adult intelligence scale (rev). New York? Psychological Company, 1981.

14 Sternberg S. High speed memory scanning: stability and gener ality. J Exp Psychol 1972;96:239-46.

15 Archer EJ. A re-evaluation of the meaningfulness of all possib CVC trigrams. Psychological monographs: general and applied 1960;74:1-23.

16 Fergusom GA. Statistical analysis in psychology and education 3rd ed. New York: McGraw Hill, 1971.

17 Weber A, Jermini C, Grandjean EP. Relationship objective assessment of experimentally induced fatigue. Ergonomics 1975;1:151-6.

18 Morgan CJ. Flicker discrimination. Physiological psychology New York; McGraw Hill, 1965.

19 Grant WM. The peripheral visual system as a target. In: Spencer PS, Schaumberg HH, eds. Experimental and clinical neus rotoxicology. Baltimore: Williams and Wilkins, 1980:77-91 을

20 Innes JM, Clarke A. Australian fire-fighters experience mor stresses away from work. Fire 1982:40. (Overseas supplement 